\title{
SEPTICEMIC SALMONELLOSIS CAUSED BY SALMONELLA HESSAREK IN WINTERING AND MIGRATING SONG THRUSHES (TURDUS PHILOMELOS) IN SPAIN
}

\author{
Roser Velarde, ${ }^{1}$ M. Concepción Porrero, ${ }^{2}$ Emmanuel Serrano, ${ }^{1}$ Ignasi Marco, ${ }^{1}$ María García, ${ }^{2}$ \\ Sonia Téllez, ${ }^{2}$ Lucas Domínguez, ${ }^{2}$ Raül Aymi, ${ }^{3}$ and Santiago Lavín ${ }^{1,4}$ \\ ${ }^{1}$ Servei d'Ecopatologia de Fauna Salvatge, Departament de Medicina i Cirurgia Animals, Facultat de Veterinària, \\ Universitat Autònoma de Barcelona, 08193 Bellaterra, Barcelona, Spain \\ ${ }^{2}$ Centro de Vigilancia Sanitaria Veterinaria (VISAVET), Universidad Complutense, Avenida Puerta de Hierro s/n, 28040 \\ Madrid, Spain \\ ${ }^{3}$ Institut Català d'Ornitologia, Museu de Ciències Naturals, Passeig Picasso, s/n, 08003 Barcelona, Spain \\ ${ }^{4}$ Corresponding author (email: Santiago.Lavín@uab.cat)
}

ABSTRACT: We investigated two mortality events in wintering and migrating Song Thrushes (Turdus philomelos) in Catalonia, northeastern Spain in 2009 and 2010. Both episodes occurred in late February to mid-March during the spring migration. Salmonellosis produced by the serotype Salmonella enterica subsp. enterica serotype Hessarek ( $S$. Hessarek) was identified as the cause of death in both episodes. Poor body condition, marked splenomegaly, and microscopic disseminated intravascular coagulation with numerous intravascular and tissular bacteria were the most consistent findings. Macro-restriction profiling by pulsed-field gel electrophoresis (PFGE) using $X b a \mathrm{I}$ was performed for epidemiologic typing of the $S$. Hessarek isolates. Two clusters were discernible, that are possibly related, with a similarity of $82.8 \%$. Analysis comparing pectoral muscle and subcutaneous fat scores from the Song Thrushes that died from $S$. Hessarek with those from healthy Song Thrushes from nearby areas during 2009 and 2010 suggest that poor body condition was associated with the $S$. Hessarek infection.

Key words: Avian mortality, Passeriformes, Salmonella Hessarek, salmonellosis, Song Thrush, Spain, Turdus philomelos, wild birds.

\section{INTRODUCTION}

Salmonellosis outbreaks regularly cause mortality in wild birds in several areas of the world (Daoust et al., 2000; Refsum et al., 2003; Hall and Saito, 2008; Pennycott et al., 2010). These outbreaks mainly affect birds of the order Passeriformes and are commonly caused by Salmonella enterica subsp. enterica serotype Typhimurium ( $S$. Typhimurium). Most of these sporadic outbreaks have been associated with the congregation of large numbers of susceptible birds at bird feeders or feeding stations. However, epizootics also occur over large geographic areas and their epidemiology is more difficult to understand (Daoust et al., 2000). Salmonella enterica subsp. enterica serotype Hessarek ( $S$. Hessarek) is regarded as an unusual serotype. It was originally isolated from a Common Raven (Corvus corax) in Iran (Neel et al., 1953) and subsequently has been detected on numerous occasions in outbreaks of septicemic salmonellosis in
European Starlings Sturnus vulgaris (Singer et al., 1977; Magistrali et al., 2008).

In late February to mid-March in the winters of 2009 and 2010, high mortalities in Song Thrushes (Turdus philomelos) were observed in Catalonia, northeastern Spain. This partially migratory thrush breeds across much of Eurasia and many birds winter in southern Europe, North Africa, and the Middle East (Cramp, 1988). In Catalonia, Song Thrushes breed mainly in humid oak and pine woodland and riparian forests in supra-Mediterranean areas but are scarce in the rest of the territory. Catalonia is also an important wintering ground for the species and lies on their migration route. Migratory birds are commonly seen in Catalonia when heading south, from September to late November, and then on their northerly return journeys, starting in February (Santos, 1982).

We isolated $S$. Hessarek from birds during two mortality events in Song Thrushes. Here we describe the gross 
and microscopic lesions, bacterial isolation, molecular characterization of the isolates, effect of the infection on body condition, and the presence of predisposing or contributing factors in the Song Thrush population.

\section{MATERIALS AND METHODS}

\section{Study area and animal collection}

The area involved in both mortality events is centered on the town of La Palma d'Ebre $\left(41^{\circ} 17^{\prime} \mathrm{N}, 0^{\circ} 40^{\prime} \mathrm{E}\right.$; county of Ribera d'Ebre, Catalonia, northeastern Spain), where the majority of the dead birds were found, but also included areas of the neighboring counties of Priorat, Segrià, and Garrigues. This area harbors extensive olive groves where the density of Song Thrushes during winter reaches 440 thrushes $/ \mathrm{km}^{2}$ (Herrando et al., 2011). Song thrushes share this area with several other species, primarily passerines. A linear transect carried out in the study area as part of the Catalan Common Bird Survey during nine successive winters (2002-2010) identified 53 species, of which the Song Thrush was the second most common (mean of 38 birds $/ \mathrm{km}$ ). Other common species in the area included Common Chaffinch (Fringilla coelebs; 85/km), European Starling, Blackcap (Sylvia atricapilla), Sardinian Warbler (Sylvia melanocephala) and Eurasian Blackbird (Turdus merula), all with densities of approximately 10/km (ICO, 2011).

Sick, moribund, and dead Song Thrushes were found in open fields, olive groves, and along roads. Hunters and others from several of the local villages and small towns reported the presence of many dead birds. It was difficult to determine the total number of dead birds because they were found scattered over a large area, and many carcasses were probably never found or were removed by scavengers. Considering these limitations, it is likely that over 1,000 birds died. In 2009, 40 birds (37 Song Thrushes, one female Eurasian Blackbird, one female European Starling, and one male White Wagtail [Motacilla alba]) were collected. In 2010, although high mortality of Song Thrushes occurred again in late February to mid-March, the number of reports of dead birds suggested the event was less severe than in the previous year. In 2010 , only three Song Thrushes were submitted for confirmation of cause of death. Carcasses were found in various stages of decomposition but were kept at $-20 \mathrm{C}$ from the time they were collected until their arrival at the necropsy facility.

\section{Gross and microscopic pathology}

Necropsies were performed on all birds on the day of their arrival. Body condition was evaluated based on the prominence of the sternum (in terms of the convexity or concavity of the pectoral muscle) and the amount of body fat using a four-point scoring technique: $0=$ muscle very concave (cross-section) with keel of sternum protruding sharply; $1=$ muscle roughly triangular in shape with keel protruding sharply; $2=$ slightly rounded muscle with keel protruding just slightly above the muscle level; and 3 = rounded muscle at the same level as, or exceeding, the keel. Subcutaneous fat (furcular and abdominal) was scored as per Kaiser (1993), in which a score from 0 (no fat) to 8 (pectoral and abdominal muscles completely covered by fat) is assigned. Body weight $( \pm 0.1 \mathrm{~g})$, sex, and lesions were recorded. Tissues samples from the brain, pectoral muscles, lungs, heart, liver, spleen, kidneys, and intestine were collected for histopathology, and tissue samples from the brain, spleen, liver, kidneys, and lungs were stored in separate sterile tubes. After necropsy, spleen samples were sent for routine microbiologic cultures. Tissue samples were not collected from birds with advanced autolysis. Tissues for histopathology were placed in $10 \%$ buffered formalin, trimmed, embedded in paraffin, sectioned at 3$4 \mu \mathrm{m}$, and stained with hematoxylin and eosin. Phosphotungstic acid hematoxylin (PTAH) staining was used to demonstrate polymerized fibrin in vessels and capillaries.

\section{Bacterial isolation and molecular typing}

We cultured 21 spleen samples (15 Song Thrushes from 2009 and three from 2010) and one each of Eurasian Blackbird, European Starling, and White Wagtail (all from 2009); all were cultured for Salmonella. Bacteria were cultured according to ISO 6579:2002/AMD 1:2007 Annex D, as recommended by the European Union Reference Laboratory for Salmonella in fecal samples (ISO, 2007). Colonies of presumptive Salmonella were confirmed as Salmonella spp. by a commercially available biochemical method: Enterotube II (BD BBL, Heidelberg, Germany). Serologic typing was performed based on the Kauffmann-White scheme (Kauffmann, 1941). Macro-restriction profiling by pulsed-field gel electrophoresis (PFGE) using $\mathrm{XbaI}$ was performed for the epidemiologic typing of $S$. Hessarek isolates according to the PulseNet protocol (PulseNet International, 2011). XbaIdigested DNA PFGE patterns were analyzed using the BioNumerics 6.5 software (Applied Math, St-Martens-Latem, Belgium). 


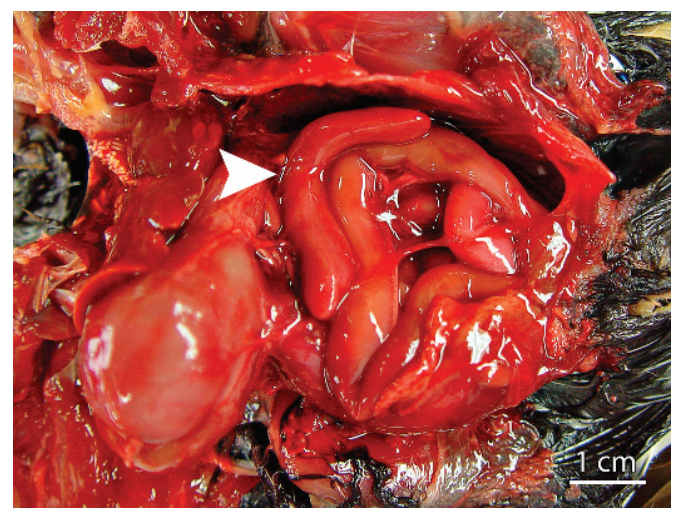

FIgURE 1. Splenomegaly in a Song Thrush (Turdus philomelos) that died of septicemic salmonellosis caused by Salmonella Hessarek, 2009-2010, Catalonia, Spain.

\section{Statistical analysis}

To explore the effect of infection on body reserves in Salmonella-infected thrushes, we compared body weight, pectoral muscle, and fat scores from dead thrushes with those from apparently healthy birds trapped in the same years as the mortality event (2009-2010). Weights and body condition scores are routinely collected and stored by the Catalan Ornithological Institute during annual banding campaigns. Whereas the body weights of captured thrushes showed no departure from the normal distribution (e.g., Skewness = $-0.53, z=-1.12, P=0.26$ and Kurtosis = $2.04, z=-0.39, P=0.69)$, both pectoral muscle and fat scores were nonnormally distributed (i.e., both ordinal variables with 3 and 6 categories). Thus, for the statistical analysis, we used a parametric Student's $t$-test for comparing body weights and a nonparametric Mann-Whitney $U$-test for comparing the fat and muscle scores of healthy and infected thrushes. Because ages of the dead birds were not recorded, the body weight and body condition of the infected thrushes were compared against those of apparently healthy young and adult thrushes. Additionally, given seasonal variation in body weight and pectoral muscle and fat scores (maximum values in late fall and early winter and minimum scores in spring and summer; data not shown), we analyzed only birds captured in February and March, the months in which mortality was seen. All analyses were conducted in $\mathrm{R}$ version 2.12.1 (R Development Core Team, 2011).

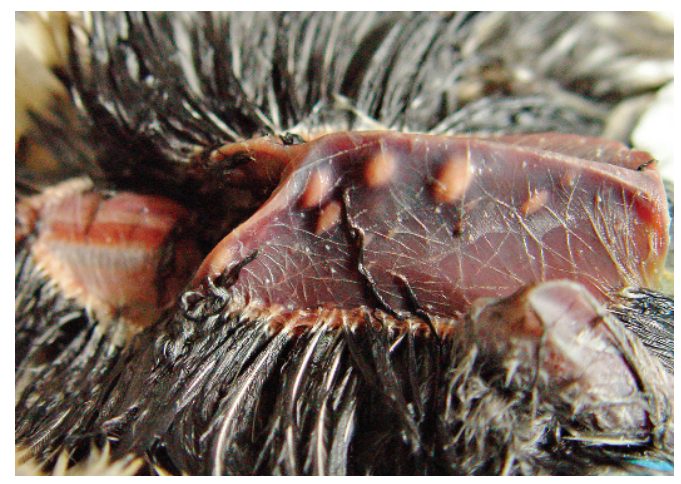

Figure 2. Multiple foci of myonecrosis and moderate granulomatous inflammation of the pectoral muscles of a Song Thrush (Turdus philomelos) that died of septicemic salmonellosis caused by Salmonella Hessarek, 2009-2010, Catalonia, Spain. Note severe pectoral muscle atrophy.

\section{RESULTS}

\section{Gross and microscopic pathology}

Thirty-four of the 40 Song Thrushes collected for analysis (37 in 2009 and three in 2010) were examined post-mortem (11 females, 22 males, one with sex not recorded). The remaining six birds (all from 2009) were not suitable for diagnostic examination. Both young and adult birds were analyzed, although the age of individual birds was not recorded. The main necropsy findings in all Song Thrushes examined were poor body condition and splenomegaly with the spleen at least twice normal size (Fig. 1). All birds showed an absence of fat deposits as well as moderate to severe pectoral muscle atrophy (scores 0 or 1). Other macroscopic findings were moderate to moderately severe hepatomegaly with occasional multifocal pinpoint foci of necrosis (six birds), fibrinous serositis (a thin layer of fibrin over the liver or intestines; four birds), hemorrhage in the proventriculus or intestine (four birds), multifocal myonecrosis in pectoral muscles (three birds; Fig. 2), and multifocal encephalitis (white pinpoint foci; one bird). In light of these findings, bacterial septicemia was suspected to be the cause of the mortalities. Concomitant lesions for septicemia and trauma (pectoral and internal 
hemorrhages) were observed in two birds. The Eurasian Blackbird examined was in fair body condition (body weight of $79 \mathrm{~g}$, pectoral muscle score of 2 , and subcutaneous fat score of 1) and had 2-mm puncture holes through the skin covering the pectoral muscle as well as pectoral muscle hemorrhage and clotted blood within the thorax adjacent to the sternum. The European Starling was in good body condition (75 g, pectoral muscle score of 2 , and subcutaneous fat score of 2 ) and also had internal hemorrhages. The White Wagtail was in fair body condition (19 g, pectoral muscle score of 2 , and subcutaneous fat score of 1) and had hemorrhages in the pectoral muscles and blood in its trachea. Trauma was suspected as the cause of death in these three birds.

Sixteen Song Thrushes were processed for histopathology (all from 2009). In many cases, autolysis and the fact that carcasses had been frozen meant that the tissues were difficult to evaluate. However, numerous bacteria and fibrin thrombi in the spleen, liver, kidneys, lungs, and less frequently in the brain were clearly identified in all birds (Fig. 3A, B), which otherwise had no other discernible lesions. After PTAH staining, we observed multifocal distribution of polymerized fibrin in glomerular capillaries and interstitial vessels in the kidneys (Fig. 3B), sinusoids and vessels in the liver, vascular sinuses in the spleen, and vessels in the lungs. Intracellular (endothelial cells and leukocytes) and extracellular coccobacilli were often present in vessels. Microscopic bacterial colonization of tissues with small necrotic foci were observed most commonly in the spleen (12/16), liver (9/16), skeletal muscle (3/16), myocardium (3/16; the same birds that had skeletal muscle lesions), kidneys (2/16), brain (2/16; Fig. 3C), and lungs (1/16). In most cases, these small necrotic foci consisted of necrotic inflammatory debris with bacterial colonies, and only in a few cases were they surrounded by mononuclear cells, mainly macrophages. In the latter cases, it was thought that the course of the disease had lasted longer. Multifocal lesions in the skeletal muscle and myocardium consisted of areas of myonecrosis characterized by a center of hypereosinophilic swollen myofibers, some with partial or extensive sarcoplasmic mineralization, surrounded by necrotic inflammatory debris and, in the periphery, bacterial aggregates and mild-to-moderate mononuclear inflammatory cell infiltrate with mainly macrophages (Fig. 3D). Hemorrhages were observed macroscopically in the intestine of four birds. However, intestinal necrosis with inflammation and hemorrhaging was only documented microscopically in one bird. The other three birds had blood in the lumen but no lesions in the mucosa. Microfilariae were identified histologically in the intravascular spaces of eight of the 16 birds examined. Based on the isolation of Salmonella spp. from the spleen samples and the microscopic lesions, septicemic salmonellosis was diagnosed. The three birds that were not Song Thrushes were processed for histopathologic examination despite their advanced state of autolysis. Microscopically, bacterial aggregates in intravascular spaces were only discernible in the wagtail.

\section{Bacterial isolation and identification}

Bacterial isolates from all 21 spleen samples were confirmed as Salmonella spp. and Salmonella enterica subsp. enterica serovar Hessarek ( $S$. Hessarek) was identified. According to the macro-restriction profile obtained by PFGE using the restriction endonuclease $X b a \mathrm{I}$, the 21 isolates could be separated into two subtypes that we have arbitrarily named subtype 1 and subtype 2 (Fig. 4). Both subtypes were found in 2009 but only subtype 1 was found in 2010. Sixteen of the isolates were subtype 1 ( $76 \%)$, including the isolates from the blackbird and the wagtail, while the five isolates of subtype 2 also included the isolate from the starling. No relationship between the PFGE profile and geographical origin of the strains was observed. XbaI-digested 

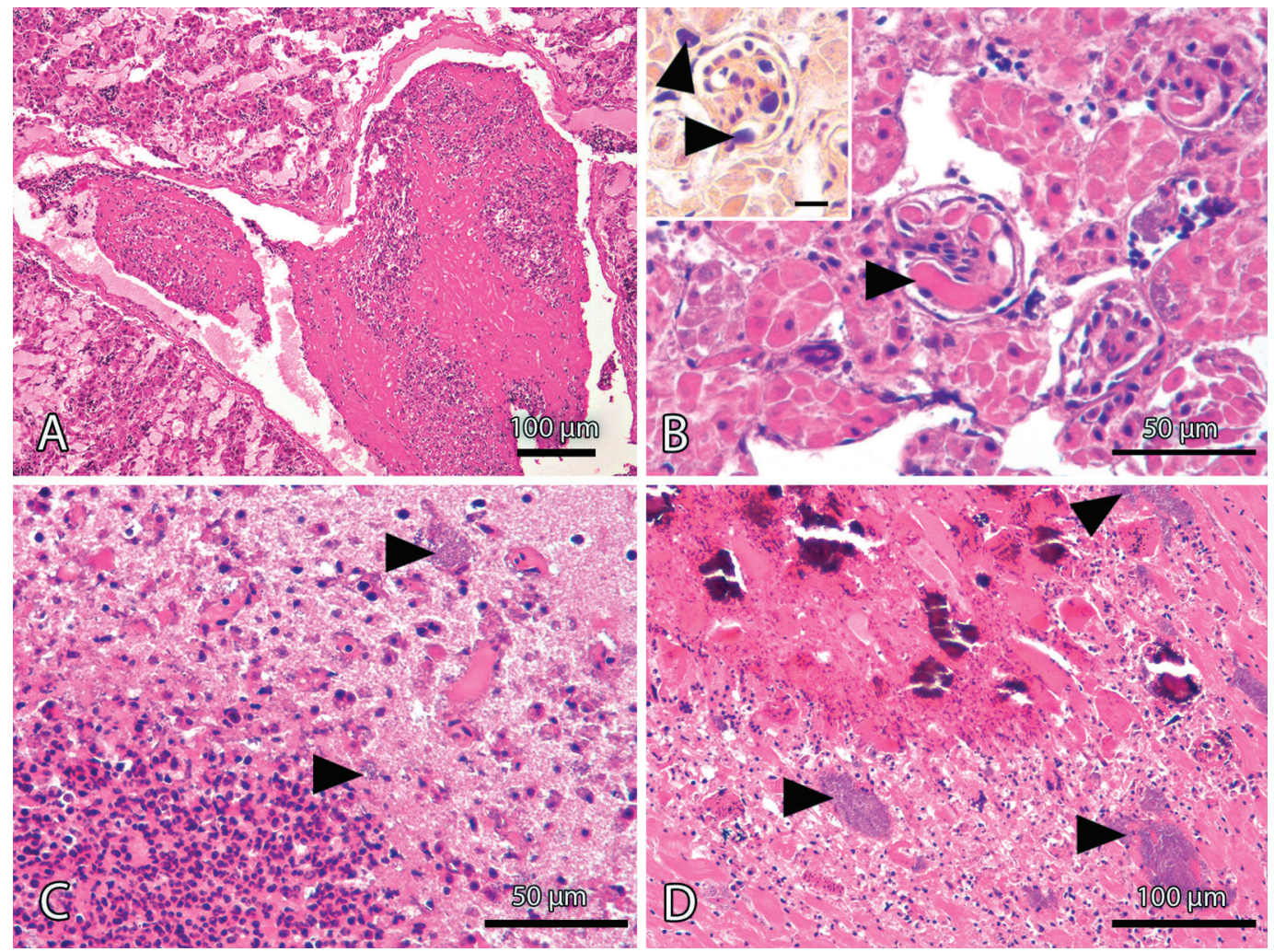

Figure 3. Microscopic lesions in Song Thrushes (Turdus philomelos) that died of salmonellosis caused by Salmonella Hessarek, 2009-2010, Catalonia, Spain. H\&E stain. A. Liver; large fibrinocellular thrombus. Freezing and thawing resulted in artifactual dilation of sinusoids. B. Kidney; thrombi in glomerular capillaries (arrowheads). Inset, phosphotungstic acid hematoxylin (PTAH)-stained section demonstrates fibrin thrombi in glomerular capillaries and interstitial vessels (arrows). Fibrin is blue-purple. Bar $=10 \mu \mathrm{m}$. C. Brain; focal inflammatory necrosis with bacterial colonies (arrows) in the cortex. D. Pectoral muscle; focally extensive myonecrosis with inflammatory debris, macrophages, and bacterial colonies (arrows). Note mineralization of several myofibers.

DNA PFGE patterns were analyzed using the BioNumerics 6.5 software and the similarity was $82.8 \%$. According to the PFGE patterns, the isolates are considered to be possibly related (Tenover et al., 1995).

\section{Statistical analysis}

The Salmonella infection had a clear correlation with both body weight and body condition of the infected thrushes (Table 1). The body weight of apparently healthy thrushes was $1.26(t=5.3, \mathrm{df}=40$, $P<0.001)$ to 1.27 times greater $(t=6.7$, $\mathrm{df}=45, P<0.001)$ than Salmonella-infected thrushes. Differences in body condition scores were even greater. The median pectoral muscle scores of apparently healthy young and adult thrushes were double those of sick birds $(\mathrm{W}=416$, $P<0.001$ vs. apparently healthy adults and $\mathrm{W}=226, P<0.001$ vs. apparently healthy young thrushes). Salmonella-infected thrushes did not have subcutaneous fat (Table 1).

\section{DISCUSSION}

We describe the first isolation of Salmonella enterica subsp. enterica serotype Hessarek and its associated disease in Song Thrushes. The genus Salmonella includes approximately 2,500 serotypes and all bird species are considered to be susceptible to the bacteria; host 


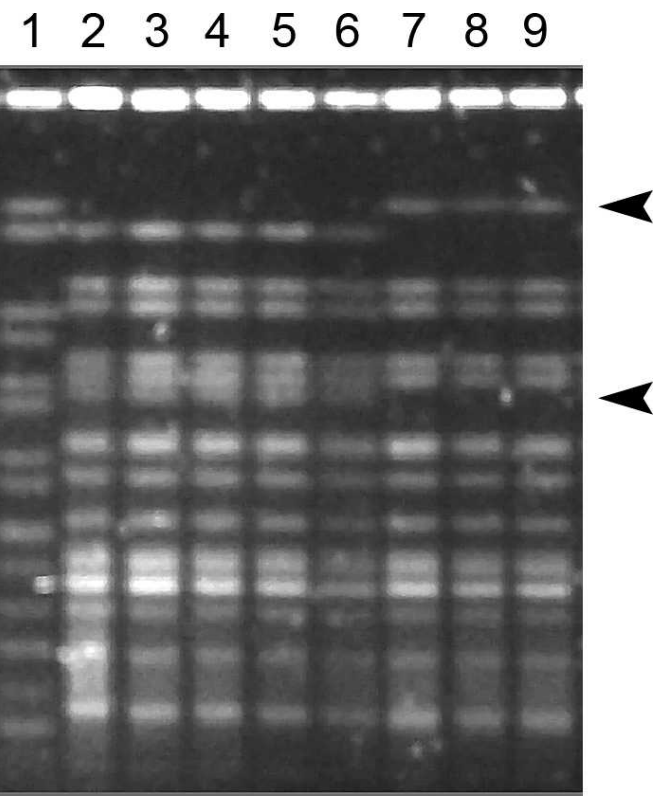

Figure 4. Pulse-field gel electrophoresis (PFGE) fingerprints for Salmonella Hessarek isolates from Song Thrushes (Turdus philomelos) from Catalonia, Spain (2009-2010) using the restriction endonuclease XbaI. Representatives of the two subtypes. Lanes: 1, strain of Salmonella serotype Braenderup (H9812) restricted with XbaI (standard); 2-6, subtype 1; 7-9, subtype 2. Arrows indicate the differences between the two subtypes.

specificity is known in some of these serotypes. When the same serotype is isolated from different species (for example, S. Typhimurium), techniques providing further discrimination have shown that specific biotypes are associated with diseases in certain species (Tizard, 2004).
This is probably the case of $S$. Hessarek and starlings. Salmonella Hessarek has been repeatedly isolated from outbreaks of septicemic salmonellosis in European Starlings (Singer et al., 1977; Magistrali et al., 2008) and experimental infection in turkeys (Meleagris gallopavo), chicks (Gallus gallus domesticus), collared doves (Streptopellia decaocto), and starlings using $S$. Hessarek confirmed that starlings are likely to die 8-28 days postinoculation (Singer et al., 1977). The other species showed no signs of disease.

Salmonella Hessarek was isolated from dead Song Thrushes in two consecutive years. The source of the infection in Song Thrushes, nevertheless, is not clear. Additional epidemiologic studies are needed to determine whether infection is occurring in the olive groves (a habitat shared by several species, including starlings) or whether a new host adaptation of this serotype to Song Thrushes is involved. Demonstration of adaptation to a new host will require a demonstration of the capacity of this serotype to circulate and persist by direct transmission within the population of Song Thrushes (Kingsley and Bäumler, 2000).

Because both wintering and migrating Song Thrushes are present in the study area during winter, it is not clear whether the mortality affected wintering or migrating thrushes more severely. Nevertheless, in both years, the die-offs persisted

TABLE 1. Body weights (range), pectoral muscle scores (0-3), and subcutaneous fat scores (0-8) for captured juvenile $(n=8)$ and adult $(n=13)$ healthy Song Thrushes (Turdus philomelos) and for thrushes that died of salmonellosis caused by Salmonella Hessarek $(n=34)$ in February and March 2009 and 2010, Catalonia, Spain.

\begin{tabular}{|c|c|c|c|c|}
\hline Health status & Age & Body weight (g) & $\begin{array}{l}\text { Pectoral muscle score, } \\
\text { Median }\left(\text { Min }^{\mathrm{b}}-\mathrm{Max}^{\mathrm{c}}\right)\end{array}$ & $\begin{array}{l}\text { Subcutaneous fat score, } \\
\text { Median }\left(\text { Min }^{\mathrm{b}}-\mathrm{Max}^{\mathrm{c}}\right)\end{array}$ \\
\hline Healthy & Juvenile & $69.6(65.7-73.2)$ & $2(1-2)$ & $1(0-3)$ \\
\hline Healthy & Adult & $70.0(60.3-77.5)$ & $2(2-2)$ & $1(0-4)$ \\
\hline Found dead & & $55.1(34.1-69.4)$ & $1(0-1)$ & 0 \\
\hline
\end{tabular}

\footnotetext{
${ }^{\text {a }} 0=$ muscle very concave with keel of sternum protruding sharply; 1 = muscle roughly triangle-shape with keel protruding sharply; 2 = slightly rounded muscle with keel protruding slightly above the muscle level; and $3=$ rounded muscle at the same level as or exceeding the keel.

${ }^{\mathrm{b}}$ Min $=$ minimum score observed.

${ }^{\mathrm{c}}$ Max $=$ maximum score observed.

${ }^{\mathrm{d}}$ Subcutaneous fat score (Kaiser, 1993): $0=$ no fat to $8=$ pectoral and abdominal muscles completely covered by fat.
} 
throughout the known northward migration (usually February and March), and there is an increase in thrush population densities in this area at this time of year. Although Song Thrushes are not as gregarious as starlings, they form loose flocks and gather in suitable feeding areas and communal drinking pools during migration. This behavior may facilitate the spread of Salmonella between individuals. The route of exposure could be fecal contamination on the ground. The Song Thrush is omnivorous and eats a wide range of invertebrates as well as soft fruits (Tejero et al., 1984). The main findings in the proventriculus were small olives, most likely taken from the ground. No predisposing factor, such as low body weight or low body condition in the nearby apparently healthy banded population of Song Thrushes, was detected. Furthermore, the wintering population during 2006-2009 was fairly stable, and the average population for the whole of Catalonia is estimated at 2.5 million thrushes (Herrando et al. 2011). Analysis during 2009 and 2010 using pectoral muscle and subcutaneous fat scores from both the Song Thrushes that died from $S$. Hessarek and healthy Song Thrushes from nearby regions suggest that poor body condition was associated with $S$. Hessarek infection.

The major pathologic findings in Song Thrushes (splenomegaly and disseminated intravascular coagulation with numerous intra- and extracellular bacteria in most tissues) are similar to those described in the starlings that died from the infection. The lesions were also similar to those described in cases of salmonellosis in Passeriformes in which the main isolated serotype is $S$. Typhimurium. However, the most characteristic features of $S$. Typhimurium infection in passerines are ingluvitis or esophagitis with necrotic plaques (Daoust and Prescott, 2008). These features were not observed in any of the 37 Song Thrushes we examined and have not been described in outbreaks of salmonellosis in starlings. Thus, these lesions may not be a feature of infection by $S$.
Hessarek. The pathology of S. Hessarek infections in starlings and Song Thrushes seems to be characteristic for this serotype in these birds. Multifocal myonecrosis has not been seen in cases of salmonellosis in starlings but has been described in birds infected with $S$. Typhimurium (Daoust and Prescott, 2008).

Pulsed-field gel electrophoresis has been shown to be effective for typing Salmonella isolates (Tizard, 2004). Using this technique and the restriction endonuclease $X b a \mathrm{I}$, two patterns were found in 2009 and one in 2010. Although the low number of isolates tested in 2010 precludes drawing definitive conclusions, this low variability may suggest a common source of infection. A wider study of $S$. Hessarek, including complementary techniques of genetic characterization such as MLST-V (Tankouo-Sandjong et al., 2007), will be necessary to elucidate the genetic variability of this serovar.

Despite the apparently high specificity and pathogenicity of $S$. Hessarek for starlings and Song Thrushes, other species may succumb to infection in the field. Susceptible species with the confirmed isolation of the same serotype include the House Sparrow Passer domesticus (Singer et al., 1977) and, as we have shown, the Eurasian Blackbird and White Wagtail.

Salmonella Hessarek has also been isolated from mammals including a case of encephalitis in a lynx (Lynx lynx) from Finland (OIE, 2005), presence in fecal samples from foxes (Vulpes vulpes) in Norway (Handeland et al., 2008), and from the ileocecal lymph nodes of freeranging pigs (Sus scrofa) in Spain (GómezLaguna et al., 2011). The source of these infections could have been the ingestion of infected birds, as is suggested in the case of $S$. Typhimurium in foxes (Handeland et al., 2008) and domestic cats (Felis catus; Tizard, 2004).

It may be significant that the increasing frequency of isolation of this serotype in wild birds coincides with its first isolation in mammals. Although these bacterial 
isolations in mammals are from relatively distant areas, they are within the migration range of the birds involved. Comparisons of isolates from starlings, Song Thrushes, and mammals are necessary to determine if they are epidemiologically related.

Salmonella Hessarek has also been associated with disease in humans in Israel (Singer et al., 1977). Because the Song Thrush is an important game bird in Spain and other countries, close contact between thrushes and humans is likely and zoonotic transmission of $S$. Hessarek from thrushes to humans is possible.

We will continue to monitor our study area to assess continued effects of $S$. Hessarek infection on Song Thrush populations and will inform the public health authorities, general public, and hunters of the zoonotic potential of this infection as well as suggest appropriate measures to be taken when handling sick or healthy (possible carriers) Song Thrushes in Catalonia.

\section{ACKNOWLEDGMENTS}

Bird samples were provided mainly thanks to the efforts of Xavier Cubells. We thank all the local people, hunters, and especially Pere López (Federal Hunting Association) and the Catalan Rural Agents for coordination, recovery, and collection of some of the carcasses. We thank Lourdes Abarca from the Departament de Sanitat i d'Anatomia Animals, Facultat de Veterinaria, Universitat Autònoma de Barcelona who performed the isolation and identification of Salmonella spp. in the first cases of the outbreak. R. Velarde is supported in part by the Spanish Ministerio de Ciencia e Innovación (Subprogram Personal Técnico de Apoyo) and The European Social Fund and E. Serrano by the Juan de la Cierva Program (MINCINN, Spain). Biometrical data on Song Thrushes banded in Catalonia were kindly provided by the Catalan Ornithological Institute (ICO). The studies realized by the Servei d'Ecopatologia de Fauna Salvatge are also funded by the Direcció del Medi Natural del Department de Medi Ambient de la Generalitat de Catalunya.

\section{LITERATURE CITED}

Cramp, S. 1988. Handbook of the birds of Europe, the Middle East, and North Africa: The birds of the western Palearctic, Vol. V. Oxford University Press, Oxford, UK, 1,136 pp.

Daoust, P. Y., and J. F. Prescott. 2008. Salmonellosis. In Infectious diseases of wild birds, N. J. Thomas, D. B. Hunter and C. T. Atkinson (eds.). Blackwell Publishing Professional, Ames, Iowa, pp. 270-288.

, D. G. Busby, L. Ferns, J. Goltz, S. McBurney, C. Poppe, and H. Whitney. 2000. Salmonellosis in songbirds in the Canadian Atlantic provinces during winter-summer 199798. Canadian Veterinary Journal 41: 54-59.

Gómez-Laguna, J., M. Hernández, E. Creus, A. Echeita, J. Otal, S. Herrera-León, and R. J. Astorga. 2011. Prevalence and antimicrobial susceptibility of Salmonella infections in freerange pigs. Veterinary Journal 190: 176-178.

Hall, A. J., And E. K. SAito. 2008. Avian wildlife mortality events due to salmonellosis in the United States, 1985-2004. Journal of Wildlife Diseases 44: 585-593.

Handeland, K., L. L. Nesse, A. Lillehaug, T. VikøRen, B. DJønNe, AND B. BergsJø. 2008. Natural and experimental Salmonella Typhimurium infections in foxes (Vulpes vulpes). Veterinary Microbiology 132: 129-134.

Herrando, S., L. Brotons, J. Estrada, S. Guallar, And M. Anton. 2011. Atles dels ocells de Catalunya a l'hivern 2006-2009. ICO/Lynx Edicions, Barcelona, Spain, 645 pp.

ICO (Institut Català d’Ornitologia). 2011. SiOC: Servidor d'informació ornitològica de Catalunya, http://www.sioc.cat. Accessed September 2011.

ISO (International Standardization Organization). 2007. ISO 6579:2002/Amd 1:2007 Annex D: Detection of Salmonella spp. in animal faeces and in environmental samples from the primary production stage, http://www.rivm.nl/crlsalmonella/ manual/anal_method/\#tcm:85-30079. Accessed October 2011 .

KAISER, A. 1993. A new multi-category classification of subcutaneous fat deposits of song-birds. Journal of Field Ornithology 64: 246-255.

Kauffmann, F. 1941. Die bakteriologie der Salmonella gruppe. Munksgaard, Copenhagen, Denmark, 393 pp.

Kingsley, R. A., And A. J. BäUmler. 2000. Host adaptation and the emergence of infectious disease: The Salmonella paradigm. Molecular Microbiology 36: 1006-1014.

Magistrali, C., M. Latini, E. Manuali, C. Neri, C. Panzieri, V. Bazzucchi, A. Zicavo, and G. Pezzotti. 2008. Cases of salmonellosis from $S$. Hessarek in European Starling (Sturnus vulgaris) in the center of Italy. Sanità Pubblica Veterinaria 49, http://indice.spvet.it/arretrati/ numero-49/005.html. Accessed September 2011. [In Italian]

Neel, R., L. Le Minor, and M. Kaweh. 1953. Une nouvelle espèce de salmonella isolée chez un 
corbeau (Corvus corax): Salmonella Hessarek. Annales de l'Institut Pasteur 85: 271-274.

OIE (World Organization for Animal Health). 2005. Report of the meeting of the OIE working group on wildlife diseases. 73rd Annual General Session of the International Committee (12 July 2011), http://www.oie.int/doc/ged/D3888.PDF. Accessed September 2011.

Pennycott, T. W., H. A. Mather, G. Bennett, and G. Foster. 2010. Salmonellosis in garden birds in Scotland, 1995 to 2008: Geographic region, Salmonella enterica phage type and bird species. Veterinary Record 166: 419-421.

Pulsenet International. 2011. International molecular subtyping network for foodborne disease surveillance, http://www.pulsenetinternational. org. Accessed September 2011.

R Developmental Core Team 2.12.1. 2011. A language and environment for statistical computing. $\mathrm{R}$ Foundation for Statistical Computing, Vienna, Austria, http://www.R-project.org. Accessed July 2011.

Refsum, T., T. Vikøren, K. Handeland, G. KapPERud, and G. Holstad. 2003. Epidemiologic and pathologic aspects of Salmonella Typhimurium infection in passerine birds in Norway. Journal of Wildlife Diseases 39: 64-72.

SAnTos, T. 1982. Migración e invernada de zorzales y mirlos (género Turdus) en la Península Ibérica.
PhD Thesis. Universidad Complutense de Madrid, Madrid, Spain, 501 pp.

Singer, N., Y. Weissman, Y. Yom-Tov, and U. MARDER. 1977. Isolation of Salmonella Hessarek from starlings (Sturnus vulgaris). Avian Diseases 21: $117-119$.

Tankouo-Sandjong, B., A. Sessitsch, E. Liebana, C. Kornschober, F. Allerberger, H. Hächler, AND L. Bodrossy. 2007. MLST-v, multilocus sequence typing based on virulence genes, for molecular typing of Salmonella enterica subsp. enterica serovars. Journal of Microbiological Methods 69: 23-36.

Tenover, F., R. Arbeit, R. Goering, P. Mickelsen, B. Murray, D. Persing, and B. Swaminathan. 1995. Interpreting chromosomal DNA restriction patterns produced by pulsed-field gel electrophoresis: Criteria for bacterial strain typing. Journal of Clinical Microbiology 33: 2233-2239.

Tejero, E., M. Soler, and I. Camacho. 1984. Alimentación del zorzal común (Turdus philomelos Brehm 1881) en olivares de la provincia de Jaén. Anales del INIA/Ser. Forestal 8: 9-32.

Tizard, I. 2004. Salmonellosis in wild birds. Seminars in Avian and Exotic Pet Medicine 13: 50-66.

Submitted for publication 5 April 2011. Accepted 1 September 2011. 